\title{
Development of Angiostrongylus costaricensis Morera and Céspedes 1971 (Nematoda: Angiostrongylidae) larvae in the intermediate host Sarasinula marginata (Semper 1885) (Mollusca: Soleolifera)
}

\author{
Cristiane L. G. F. Mendonça • Omar S. Carvalho • \\ Ester M. Mota $\cdot$ Henrique L. Lenzi
}

Received: 8 October 2007 / Accepted: 29 November 2007 / Published online: 22 February 2008

(C) Springer-Verlag 2007

\begin{abstract}
In life cycle of Angiostrongylus costaricensis, veronicellidae mollusks participate as the invertebrate host while rodents as the main vertebrate host. The current work shows a sequential larval development of $A$. costaricensis in Sarasinula marginata, individually killed and digested from day 1 to 43, post infection. Some larvae, recovered from sedimentation, were submitted to selective staining after paraffin embedded or inclusion in JB-4 to study inner structures. As control, four slugs were used, two killed at the beginning of infection and the others at the end of the experiment. At day 2 post infection, larvae were motionless and thick, presenting initial retention of granules. At day 4, $\mathrm{L}_{2}$ were detected, persisting until 43 days post infection. Larvae $\mathrm{L}_{2}$ displayed a large amount of granules rich in lipids and carbohydrates through its overall body, with more accumulation at the medial third corresponding to the esophagus-intestine transition site. Lipid granules, the main energetic source, were located at the basal and apical regions of intestinal cells. Both $\mathrm{L}_{1}$ and $\mathrm{L}_{3}$ presented bilateral alae, which is also common in other nematodes. Transition forms between $\mathrm{L}_{2}$ to $\mathrm{L}_{3}$ molts were also observed.
\end{abstract}

C. L. G. F. Mendonça · O. S. Carvalho $(\bowtie)$

Laboratory of Intestinal Helminthiasis,

Centro de Pesquisa René Rachou/Fiocruz,

Avenida Augusto de Lima 1715,

CEP 30190.002 Belo Horizonte, Minas Gerais, Brazil

e-mail: omar@cpqrr.fiocruz.br

E. M. Mota $\cdot$ H. L. Lenzi

Department of Pathology, Instituto Oswaldo Cruz/Fiocruz,

Av Brasil 4365,

CEP 21040.900 Rio de Janeiro, Rio de Janeiro, Brazil

\section{Introduction}

The Metastrongilidae Angiostrongylus costaricensis Morera and Céspedes 1971, order Strongylida and family Angiostrongylidae, is a heteroxenic parasite. Throughout its life cycle, adult worms are located into rodent mesenteric arteries, requiring veronicellidae mollusks as intermediate hosts. The first description on its evolutionary cycle was performed by Morera (1973) and further revisions have added extensive data to the cycle both in vertebrates (Mota and Lenzi 1995, 2005) and invertebrates (Mendonça et al. 1999, 2003).

Studies have demonstrated that the nematode larval development in mollusks may be influenced by environmental factors such as humidity, temperature, estivation, intern factors such as infection intensity, and specific characteristics of the host like age, size, and susceptibility (Cheng and Alicata 1965; Gerichter 1948; Guilhon and Gaalon 1969; Halvorsen and Skorping 1982; Hori et al. 1985; Ishii 1984; Kutz et al. 1999; Rachford 1976; Rose 1957; Samson and Holmen 1984; Solomon et al. 1996; Yousif and Lammler 1975; Wallace and Rosen 1969; Kutz et al. 2001; Lv et al. 2006; Jenkins 2006).

The current work detailed sequential morphological aspects of $A$. costaricensis larval development in the intermediate host, characterizing the main chemical composition of the larvae body, the cells responsible for lipid secretion and the sequential structural modifications in the molting process from $\mathrm{L}_{1}$ to $\mathrm{L}_{3}$ stages.

\section{Materials and methods}

A total of 185 slugs, weighting around $1.0 \mathrm{~g}$, were infected with $5,000 \mathrm{~L}_{1}$ during $24 \mathrm{~h}$. Five slugs were killed daily, for 
each period of time, as follows: from the first to 30th day and at 33, 34, 35, 36, 40, 41 and 43 days post infection. They were individually digested $(\mathrm{HCl}+$ pepsin $)$ and the sediment was recovered in Petri dishes and examined with inverted microscope for $\mathrm{L}_{1}, \mathrm{~L}_{2}$, and $\mathrm{L}_{3}$ identification, according to Morera (1973).

Purified larvae were stained with Sudan Black and Oil Red (Pearse 1968) to verify the presence of lipids. For negative control, larvae were previously treated with xylol and alcohol for grease dissolution, followed by another Sudan staining.

Search for glycoprotein was performed with periodic acid-Schiff (PAS) staining and fluorescence assay using Glycine max (soybean) and Lens culinaris (Lentil)-fluorescein isothiocyanate (FITC) labeled. Amylase digestion was used as control of PAS reaction to glycogen.

The $\mathrm{L}_{1}, \mathrm{~L}_{2}$ and $\mathrm{L}_{3}$ were also fixed in Carson's formalin (Carson et al. 1973) and washed and embedded in hydrophilic resin JB-4 (Junqueira et al. 1979); this procedure excluded the alcoholic dehydration as a requirement for resin infiltration. Semi-thin sections obtained with ultracut microtome (Leica) were stained with Lee's methylene blue-basic fuchsine (Bennett et al. 1976).

Stained sections were analyzed by bright-field microscopy and entire larvae were studied by laser scanning confocal microscopy (LSM-410, Zeiss), applying reflected mode to fluorescein labeled material, while unstained larvae were seen under Nomarski mode.

\section{Results}

At day 2 post infection, $\mathrm{L}_{1}$ were thick and motionless with initial expression of lipid granules. At day $4, \mathrm{~L}_{2}$ were detected, persisting until day 43 post infection. Throughout the molting process, larval thickness varied from thin with few granules, when young, to thick with a great amount of granules, after maturation (Figs. 1a,b and 2).

Together with mature $L_{2}$, young $L_{3}$ were found with residual cuticle (Fig. 1c) at days 11, 15, 18, 20 and 28 post infection. Concomitant mature $\mathrm{L}_{3}$ and $\mathrm{L}_{2}$ and young $\mathrm{L}_{3}$ were observed at days 11, 14, 15, 16, 18, 21, 22, 26, 28 and 43 post infection.

Larvae $\mathrm{L}_{2}$ displayed a great amount of lipid granules throughout the whole body, with more density in the medial third, corresponding to the esophagus-intestine transition site (Fig. 2a-c). Granules varied in size and initially were more homogeneously distributed and, throughout molting from $L_{2}$ to $L_{3}$, they gradually moved to the subnuclear region of the intestinal epithelium (Fig. 3a,b), disappearing in mature $\mathrm{L}_{3}$ (Fig. 3c). Lipid nature of granules was confirmed by a previous treatment with xylol and alcohol, turning Sudan staining completely negative.

Larvae $\mathrm{L}_{2}$ were PAS positive, indicating the presence of neutral glycoproteins which did not vanish after amylase digestion, precluding the glycogen presence. Larvae $\mathrm{L}_{1}$ and $\mathrm{L}_{3}$ were not stained by Sudan and PAS.

G. max-FITC and L. culinaris-FITC lectins, with affinity for $N$-acetyl-D-galactosamine, $\alpha-d$-manosyl and $\alpha-d$-glycosyl, respectively, developed granules strongly stained and located predominantly in the medial third of $\mathrm{L}_{2}$ (Fig. 2d). The density of carbohydrate granules was lower when compared with the lipid ones, mainly at the ends of larval body. Lectins also developed, besides large granules, a diffuse and thin granular pattern, more evident in the medial and proximal thirds of the larval body.

Larvae $\mathrm{L}_{1}$ and $\mathrm{L}_{3}$ presented typical bilateral alae (Fig. 3c,d).
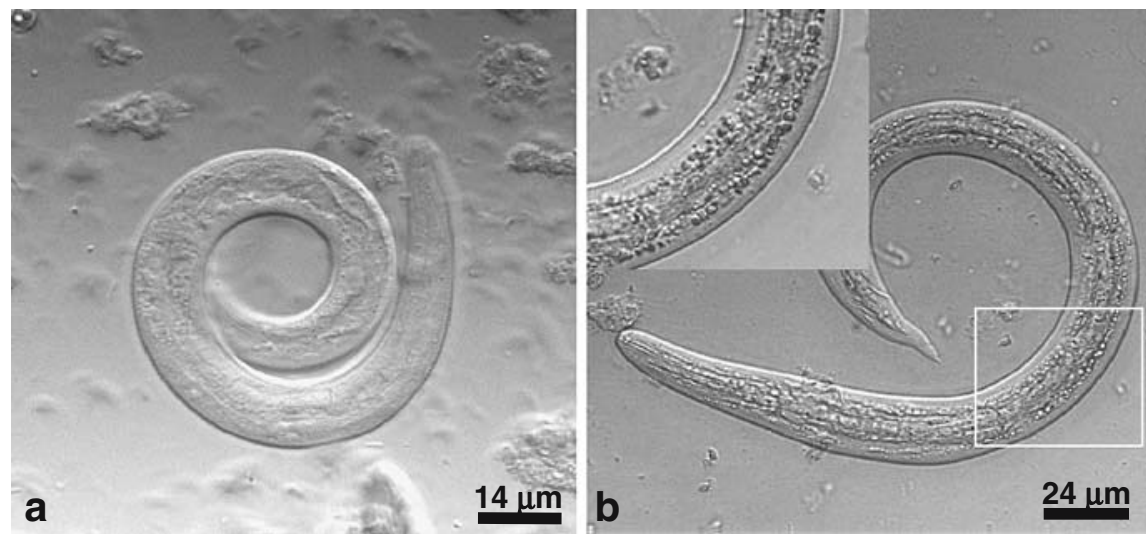

Fig. 1 Larvae of Angiostrongylus costaricensis in different stages of development. a External aspect of $\mathrm{L}_{1}$ (DIC, LSCM, Bar=14 $\left.\mu \mathrm{m}\right)$. b $\mathrm{L}_{2}$ undergoing $\mathrm{L}_{3}$ with lipids lining up close to the cuticle. The inset details the lipid granules display (DIC, LSCM, Bar $=24 \mu \mathrm{m}$ ). $\mathbf{c}$ Young $\mathrm{L}_{3}$ with residual $\mathrm{L}_{2}$ cuticle (DIC, LSCM, Bar=27 $\mu \mathrm{m}$ ). DIC=Differential interference contrast, $\mathrm{LSCM}=$ laser scanning confocal microscopy 
Fig. 2 a Larvae $L_{2}$ with many lipid granules, diminishing in the anterior end, seen in color code, from tomography sections (LSCM). b Larvae $\mathrm{L}_{2}$ with OilRed-stained lipid granules (LSCM, reflection mode). c Molting larvae $\mathrm{L}_{2}$ showing residual cuticle and lipid granules in peripheral location (LSCM). d Larvae $\mathrm{L}_{2}$ with Glycine maxFITC-positive dense granules at the medial third, with a shortage at the extremities, mainly in the anterior end (Glicine max-FITC, LSCM). FITC=Fluorescein isothiocyanate, LSCM=laser scanning confocal microscopy
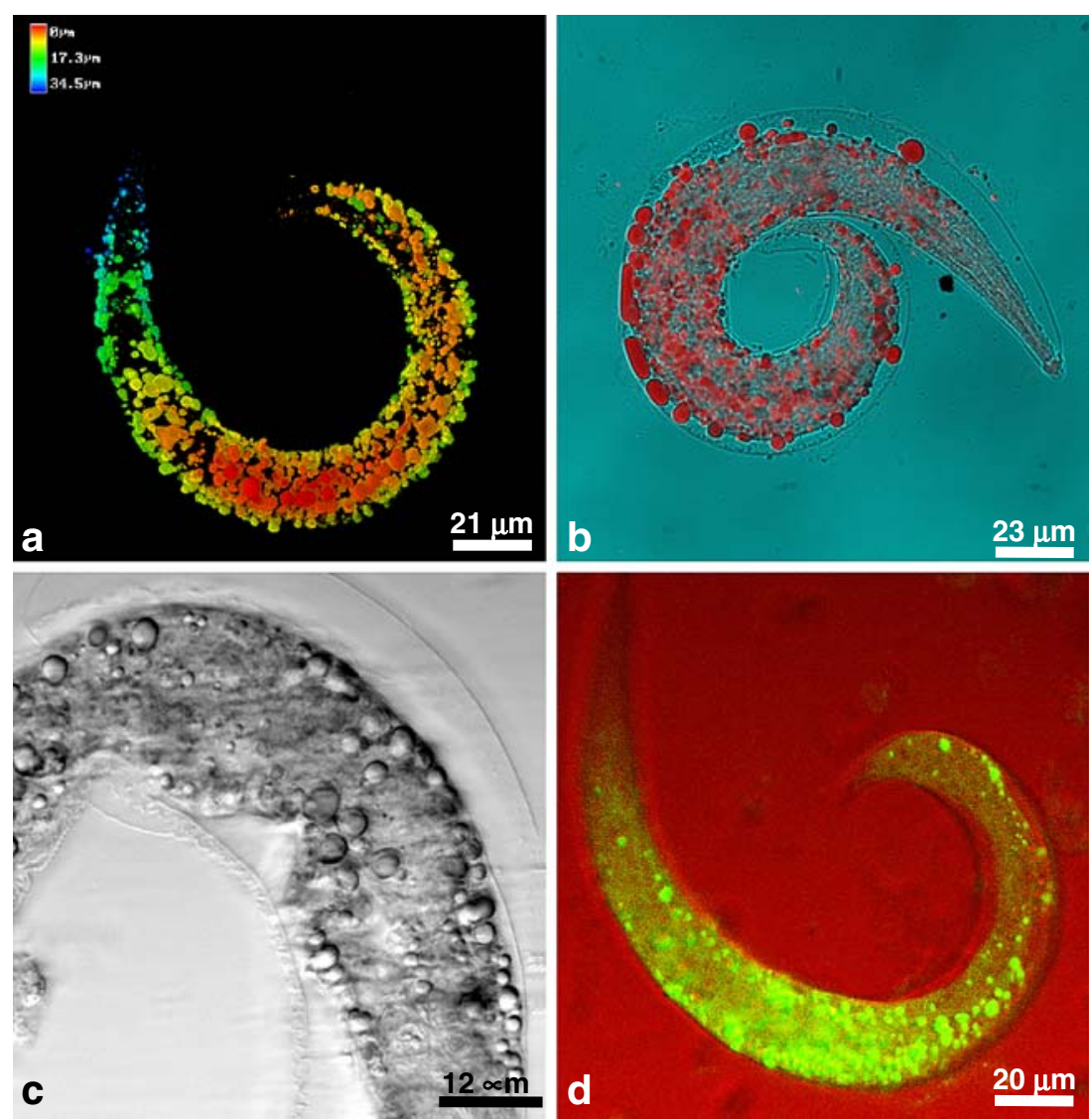

\section{Discussion}

The present work focused on morphological and biochemical characteristics of $A$. costaricensis larvae in the invertebrate host Sarasinula marginata, using diverse methodological analysis. It is demonstrated that the second molt $\left(\mathrm{L}_{2} \rightarrow \mathrm{L}_{3}\right)$ occurred from day 4 to 43 post infection, and the main energetic source of $\mathrm{L}_{2}$ consisted of lipids and carbohydrates, which were predominantly located in the medial third of the larvae, corresponding to the esophagusintestine transition site and primordial genital system.

The first description of $A$. costaricensis life cycle in the intermediate host, reported by Morera (1973), referred the rapid changes that occurred in $\mathrm{L}_{1}$, which became thicker due to the accumulation of numerous granules. Such transformations were more evident at day 3 and 4, when the first molt $\left(\mathrm{L}_{1} \rightarrow \mathrm{L}_{2}\right)$ took place. Larvae $\mathrm{L}_{2}$ grew bigger from day 4 to 10 , presenting a gradual increase in the amount of granules, making the visualization of inner organs very difficult. The second molt $\left(\mathrm{L}_{2} \rightarrow \mathrm{L}_{3}\right)$ was observed from day 11 to 14 . Between 16 and 19 days, larvae reached maturity, the moment at which they became infective to the vertebrate host.

In the current study, the second molting period $\left(\mathrm{L}_{2} \rightarrow \mathrm{L}_{3}\right)$ was longer and extended up to day 43 . This event could be related to the low temperature during the cold weather (May, June, and July) in Brazil, a natural factor able to delay a larval development in its intermediate host. Indeed, Graeff-Teixeira et al. (1991) observed that a seasonal transmission of $A$. costaricensis in the south of Brazil (late spring and early winter) might be due to ecological factors associated with the parasite-host interaction. At low temperatures, larvae evolution in the mollusk may be delayed and in the presence of heat and humidity they keep evolving, which coincides with their highest activity and the mollusks reproduction, enhancing chances to reach man.

A similar pattern was also observed in Angiostrongylus cantonensis (Yousif and Lammler 1975; Ishii 1984; Hori et al. 1985; Lv et al. 2006), Angiostrongylus vasorum (Guilhon and Gaalon 1969), Umingmastrongylus pallikuukensis (Kutz et al. 1999; Kutz et al. 2001), Protostrongylus spp (Samson and Holmen 1984), Elaphostrongylus rangiferi (Skorping 1984; Schjetlein and Skorping 1995), Cystocaulus ocreatus (Gerichter 1948), Muellerius capillaris (Gerichter 1948; Rose 1957) and Parelaphostrongylus odocoilei (Jenkins 2006) for which a strong association between temperature, larval development and infection rates in invertebrate hosts was shown. Other factors have also been mentioned as possible interference agents in 


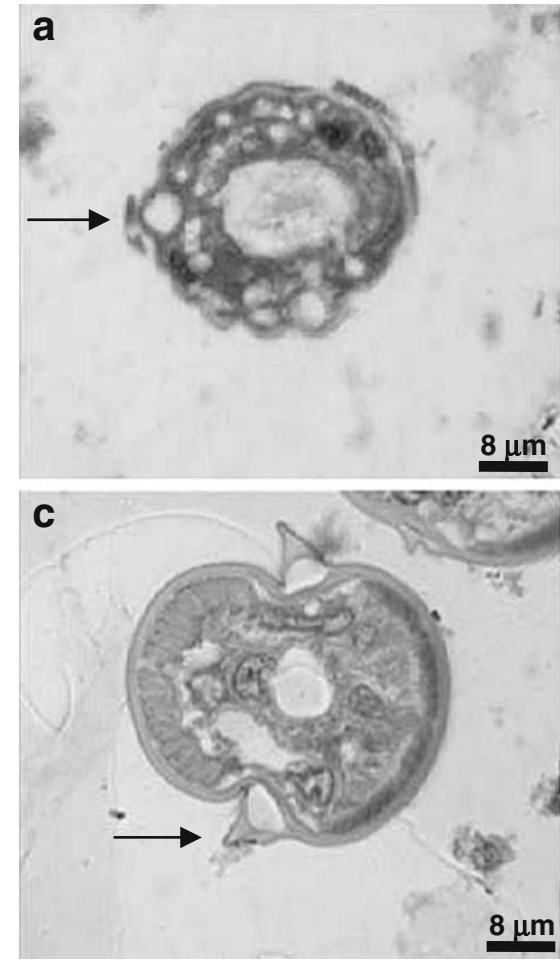

Fig. 3 a Transversal section of $L_{2}$ showing lipid drops in intestinal epithelial cells, which are located at a supra and subnuclear positions in the cytoplasm (arrow; JB-4 resin, MBBF). b Molting $\mathrm{L}_{2}-\mathrm{L}_{3}$, with a decrease in lipid vacuoles, displayed in a line position tending to the basal region of intestinal epithelial cells (arrow; JB-4 resin, MBBF). c Transversal section of L3: intestinal lumen and epithelium; cells

larval cycles of nematodes in their snail hosts such as age (Cabaret 1987; Cheng and Alicata 1965; Wallace and Rosen 1969), parasitic load (Gerichter 1948), susceptibility (Gerichter 1948; Halvorsen and Skorping 1982), lack of nutrients - aestivation (Solomon et al. 1996), and the host constitution (Rachford 1976). Therefore, we also believe that temperature may be the main environmental factor that directly influences larval development of Metastrongilidae, which constitutes important data in epidemiology and cycle maintenance in laboratory.

The main energetic source of parasite nematodes is glycogen, but during free-living life cycle lipid is the main one. Such reserves may be kept in hypoderm, into muscular cells and epithelial cells of intestine and reproductive organs.

During the larval period, lipid is kept in intestine and during encapsulating phase, in intestine lume (Rey 2001). Other studies have shown that the stored granules in intestinal cells used as energetic source consisted of glycogen and fat. Herein, Sudan Black and Oil red staining substantiated the predominant lipid composition of the granules during $\mathrm{L}_{2}$ phase (Fig. 2a,b), which additionally contain also carbohydrate and/or glycoprotein, without evidence of glycogen. The carbohydrate content was
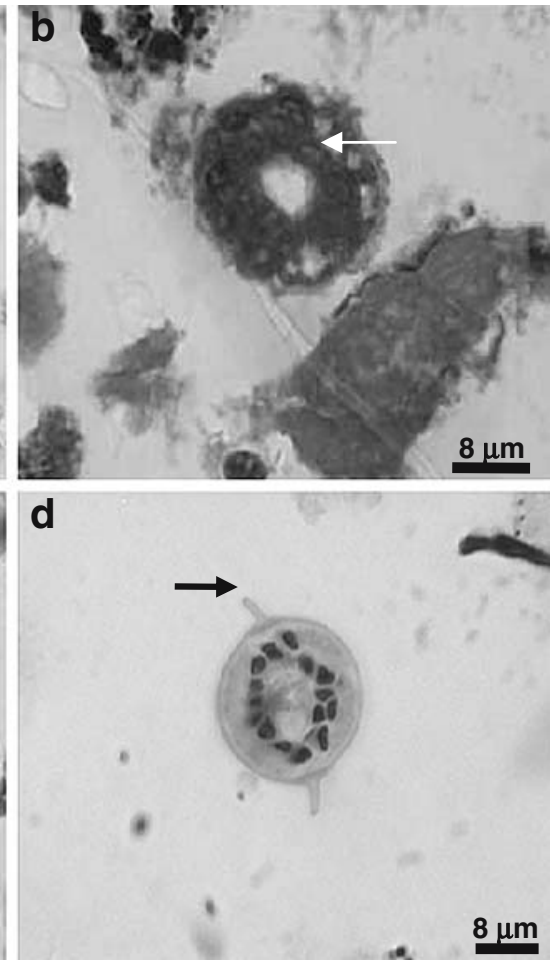

located between intestinal epithelium and cuticle, muscular layer and prominent bilateral alae (arrow; JB-4 resin, MBBF). d Transversal section of $\mathrm{L}_{1}$ at the esophagus level showing bilateral alae (semi-thin section, JB-4 resin, MFB, Bar $=8 \mu \mathrm{m}$ ). MBBF=Lee's methylene bluebasic fuchsine

partially constituted of $N$-acetyl-D-galactosamine and $\alpha$ manosyl and $\alpha-d$-glycosyl (Fig. 2d). Therefore, lipid and carbohydrate (glycolipid, glycoproteins...) were the main energetic source, not glycogen, implicated in the following larval development phase $\left(\mathrm{L}_{3}\right)$.

Analysis of the semi-thin sections (JB-4) of $\mathrm{L}_{2}$ demonstrated that lipid granules were secreted by intestinal cells, which are located at a supra and subnuclear positions in the cytoplasm (Fig. 3a). During the transition of $\mathrm{L}_{2} \rightarrow \mathrm{L}_{3}$, lipid moved preferentially to the subnuclear region of such cells (Fig. 3b), which probably, also synthesizes the glicídios.

The metabolic process which is triggered in the consumption of a large amount of synthesized lipid and glycoprotein during $\mathrm{L}_{2}$ stage is still unknown. Some nematode use acetyl $\mathrm{CoA}$, derived from $\beta$-oxidation of fatty acid, in order to make use of it during the Krebs cycle (Roberts and Janovy 2000). Probably, as in Ancylostoma tubaeforme Dubini 1843 and Haemonchus contortus Rud 1803 (Onwuliri 1985), larvae $\mathrm{L}_{1}$ and $\mathrm{L}_{2}$ of $A$. costaricensis are anaerobic, while infective $\mathrm{L}_{3}$ are aerobic and able to perform $\beta$ oxidation of a great quantity of lipid synthesized by $\mathrm{L}_{2}$.

This is the first report in the literature that emphasizes some internal morphological and biochemical characteristics of $\mathrm{L}_{2}$ 


\section{References}

Bennett HS, Wyrick AD, Lee SW, McNeil JH (1976) Science and art in preparing tissues embedded in plastic for light microscopy with special reference to glycol methacrylate glass knives and simple stains. Stain Technol 51:71-97

Cabaret J (1987) Age susceptibility of molluscan intermediate hosts to protostrongylid nematodes. Am Soc Parasitol 73:557-858

Carson FL, Martin JH, Lynn JA (1973) Formalin fixation for electron microscopy: a re-evaluation. Am J Clin Pathol 59:365-375

Cheng TC, Alicata JE (1965) On the mode of infection of Achatina fulica by the larvae of Angiostrongylus cantonensis. Malacologia 2:267-274

Gerichter CB (1948) Observation on the life cycle history of lung nematodes using snails as intermediate hosts. A J Vet Res 9:109-112

Graeff-Teixeira C, Camillo-Coura L, Lenzi HL (1991) Clinical and epidemiological studies on abdominal angiostrongyliasis in southern Brazil. Rev Inst Med Trop São Paulo 33:375-380

Guilhon J, Gaalon A (1969) Evolution larvaire d'un nématode parasite de l'appariel circulatoire du chien dans l'organisme de mollusques dulçaquicoles. C R Acad Sci 268:612-615

Halvorsen O, Skorping A (1982) The influence of temperature on growth and development of the nematode Elaphostrongylus rangiferi in the gastropods Arianta arbustorum and Euconulus fulvus. Oikos 38:285-290

Hori E, Yamaguchi K, Fujimoto K, Nishina M, Takahashi M (1985) Experimental studies on the development of Angiosttongylus cantonensis larvae in mollusks: development under low temperatures. Jap J Parasit 34:272-284

Ishii AI (1984) Effects of temperature on the larval development of Angiostrongylus cantonensis in the intermediate host, Biomphalaria glabrata. Z Parasitenkd 70:375-379

Jenkins EJ (2006) Bionomies of larvae of Paralaphostrongylus odocoilei (Nematoda: Protostrongylidae) in experimentally infected gastropod intermediate hosts. J Parasitol 92:298-305

Junqueira LCU, Bignolas G, Brentani R (1979) Picrosirius staining plus polarization microscopy, a specific method for collagen detection in tissue sections. Histochem J 11:447-455

Kutz SJ, Hoberg EP, Polley L (1999) Experimental infections of muskoxen (Ovibos moschatus) and domestic sheep with Umingmakstrongylus pallikuukensis (Nematoda: Protostrongylidae): parasite development, population structure and pathology. Can J Zool 77:1562-1572

Kutz SJ, Hoberg EP, Polley L (2001) Umingsmakstrongylus pallikuukensis (Nematoda: Prothostrongylidae) in fastrops: larval morphology, morphometrics and development rate. J Parasitol $87: 527-535$

Lv S, Zhou XN, Zhang Y, Liu HX, Zhu D, Yin WG, Steinmann P, Wang XH, Jia TW (2006) The effect of temperature on the development of Angiostrongylus cantonesis (Chen 1935) in Pomacea canaliculata (Lamarck 1822). Parasitol Res 99:583-587

Mendonça CLF, Carvalho OS, Mota EM, Pelajo-Machado M, Caputo LFG, Lenzi HL (1999) Penetration sites and migratory routes of Angiostrongylus costaricensis in the experimental intermediate host (Sarasinula marginata). Mem Inst Oswaldo Cruz 94:549-556

Mendonça CLF, Carvalho OS, Mota EM, Pelajo-Machado M, Caputo LFG, Lenzi HL (2003) Angiostrongylus costaricensis and experimental infection of Sarasinula marginata-II. Elimination routes. Mem Inst Oswaldo Cruz 98:893-898

Morera P (1973) Life history and redescription of Angiostrongylus costaricencis Morera and Céspedes, 1971. Am J Trop Med Hyg 22:613-621

Mota EM, Lenzi HL (1995) Angiostrongylus costaricensis life cycle: a new proposal. Mem Inst Oswaldo Cruz 90:707-709

Mota EM, Lenzi HL (2005) Angiostrongylus costaricensis: complete redescription of the migratory pathways based on experimental Sigmodon hispidus infection. Mem Inst Oswaldo Cruz 100:407-420

Pearse AGE (1968) Histochemistry. Theoretical and applied. J \& A Churchill, London

Rachford FW (1976) Host-parasite relationship of Angiostrongylus cantonensis in Lymnaea palustris I. Intramolluscan larval growth and development. Exp Parasitol 39:377-381

Rey L (2001) Nematóides parasitos do homem. In: Rey L (ed) Parasitologia. Guanabara Koogan S.A., Rio de Janeiro, pp 549-561

Roberts LS, Janovy J Jr (2000) Gerald D. Schmidt \& Larry S. Robert's foundations of parasitology. McGraw-Hill, Dubuque

Rose JH (1957) Observations on the larval stages of Muellerius capillaris within the intermediate hosts Agriolimax agrestis and A. reticulatus. J Helminthol XXXI:1-16

Samson J, Holmen JC (1984) The effect of temperature on rates of development of larval Protostrohgylus spp. (Nematoda: Metastrongyloidea) from bighorn sheep, Ovis canadensis canadensis, in the snail Vallonia pulchella. Can J Zool 63:1445-1448

Schjetlein J, Skorping A (1995) The temperature threshold for development of Elaphostrongylus rangiferi in the intermediate host: an adaptation to winter survival? Parasitology 111:103-110

Skorping A (1984) Density-dependent effects in a parasitic nematode, Elaphostrongylus rangiferi, in the snail intermediate host. Oecologia 64:34-40

Solomon A, Paperna I, Markovics A (1996) The influence of aestivation in land snails on the larval development of Muellerius ef. capillaris (Metastrongyloidea: Protostrongylidae). Int Parasitol 26:363-367

Wallace GD, Rosen L (1969) Studies on eosinophilic meningitis. V. Molluscan hosts of Angiostrongylus cantonensis on Pacific Islands. Amer J Trop Med Hyg 18:206-217

Yousif F, Lammler G (1975) The effect of some biological and physical factors on infection of Biomphalaria glabrata with Angiostrongylus cantonensis. Parasitol Res 47:191-201 